University of South Carolina

Scholar Commons

$9-4-2012$

\title{
Energy Storage Characteristics of a New Rechargeable Solid Oxide Iron-Air Battery
}

\author{
Xuan Zhao \\ University of South Carolina - Columbia, zhao53@email.sc.edu \\ Nansheng Xu \\ University of South Carolina - Columbia, xun@cec.sc.edu \\ Xue Li \\ University of South Carolina - Columbia, lixue@cec.sc.edu \\ Yunhui Gong \\ Kevin Huang \\ University of South Carolina - Columbia, huang46@cec.sc.edu
}

Follow this and additional works at: https://scholarcommons.sc.edu/emec_facpub

Part of the Mechanical Engineering Commons

\author{
Publication Info \\ Published in RSC Advances, Volume 2, Issue 27, 2012, pages 10163-10166. \\ CRCS Advances (2012), Royal Society of Chemistry. \\ This article cannot be redistributed or further made available. \\ This article was first published by the Royal Society of Chemistry and can be found at http://dx.doi.org/ \\ 10.1039/C2RA21992A \\ Zhao, X., Xu, N., Li, X., Gong, Y., \& Huang, K. (2012). Energy Storage Characteristics of a New Rechargeable \\ Solid Oxide Iron-Air Battery. RSC Advances, 2 (27), 10163 - 10166. http://dx.doi.org/10.1039/C2RA21992A
}




\title{
RSC Advances
}

\section{Energy storage characteristics of a new rechargeable solid oxide iron-air battery $\dagger$}

\author{
Xuan Zhao, Nansheng Xu, Xue Li, Yunhui Gong and Kevin Huang* \\ Received 30th August 2012, Accepted 4th September 2012 \\ DOI: 10.1039/c2ra21992a
}

Cost effective and large scale energy storage is critical to renewable energy integration and smart-grid energy infrastructure. Rechargeable batteries have great potential to become a class of cost effective technology suited for large scale energy storage. In this paper, we report the energy storage characteristics of a newly developed rechargeable solid oxide iron-air battery. Investigations of the battery's performance under various current densities and cycle durations show that iron utilization plays a determining role in storage capacity and round-trip efficiency. Further studies of the battery's cycle life reveal a unique chargecycle originated degradation mechanism that can be interpreted by a combined vapor-phase transport and electrochemical condensation model. Overall, the energy capacity of the new solid oxide iron-air storage battery should be properly balanced with the round-trip efficiency at optimized iron utilization.

Cost effective and large scale energy storage is essential to the growth of the future's "green energy" infrastructure. Rechargeable batteries and supercapacitors, or a hybrid form of the two, offer a number of advantages over the conventional large scale siting- and geographyconstrained pumped-water and compressed-air energy storage systems. ${ }^{1-6}$ However, rechargeable batteries and supercapacitors will need many breakthroughs in material design and system integration to become commercially viable. In an effort to advance rechargeable batteries towards an efficient, cost competitive energy storage product, we have recently demonstrated proof-of-concept of a new rechargeable solid oxide metal-air battery. ${ }^{7}$ The new battery combines a regenerative solid oxide electrochemical cell (RSOEC) and a redox cycle unit (RCU) for energy storage. The RSOEC serves as the "electrical functioning unit", alternating between the fuel cell and electrolyzer modes to realize the discharge and charge cycles, while the RCU acts as the "energy storage unit", converting electrical-chemical energy in situ via a $\mathrm{H}_{2} / \mathrm{H}_{2} \mathrm{O}$-mediated metal/metal oxide redox reaction. Fig. 1 shows a schematic of the working principle. The resultant overall chemical reaction occurring inside the battery is essentially a metal-air reaction:

Department of Mechanical Engineering, University of South Carolina, SC, 29208, USA

$\dagger$ Electronic Supplementary Information (ESI) available. See DOI: 10.1039/ c2ra21992a

$$
\mathrm{Me}+\mathrm{x} / 2 \mathrm{O}_{2} \underset{\text { charge }}{\stackrel{\text { discharge }}{\longleftarrow}} \mathrm{MeO}_{\mathrm{X}}
$$

Among many features of the new battery are three key characteristics: high energy capacity, enabled by multiple-electron charge transfer; fast charging and discharging, resulting from the decoupling of the "energy storage unit" from the "electrical functioning unit", and the use of earth-abundant and environmentally benign iron-based redox energy storage materials.

In this paper, we present new results regarding the energy storage characteristics of this new type of "metal-air" battery as a continued effort from our previous proof-of-concept work. ${ }^{7}$ The studied battery consists of a $\mathrm{ZrO}_{2}$-based RSOEC and an Fe-based RCU. The former utilizes a $150 \mu \mathrm{m}$ thick $\mathrm{ZrO}_{2}$-based electrolyte disc, as the support for a $50 \mu \mathrm{m}$ thick $\mathrm{Ni}-\mathrm{ZrO}_{2}$-based electrolyte/Ni-GDC fuel electrode, and a $50 \mu \mathrm{m}$ thick LSM-GDC air-electrode. The latter contains an $\mathrm{Fe}-\mathrm{FeO}$ redox couple supported on $\mathrm{ZrO}_{2}$. Details about battery assembly can be found in Electronic Supplementary Information. $\uparrow$ The first result is related to the phase evolution of iron oxides during the $\mathrm{H}_{2}$-reduction process. The RSOEC's Electromotive Force (EMF) is conveniently used as an indicator of the phase equilibrium. For a ternary system like $\mathrm{Fe}-\mathrm{O}-\mathrm{H}$ under an isothermal and isobaric condition, Gibbs' phase rule defines only one independent intensive variable for a two-phase system; the independent variable in this case is the partial pressure of oxygen, $p_{\mathrm{O}_{2}}$, or the ratio of partial pressure of $\mathrm{H}_{2} \mathrm{O}$ and $\mathrm{H}_{2}, p_{\mathrm{H}_{2} \mathrm{O}} / p_{\mathrm{H}_{2}}$. The fixed $p_{\mathrm{O}_{2}}$ (or $p_{\mathrm{H}_{2} \mathrm{O}} / p_{\mathrm{H}_{2}}$ ) yields a constant EMF in an oxygen concentration cell like RSOEC. The EMFs in Fig. 2(a) were recorded as a function of time during an $\mathrm{H}_{2}$-reduction process at $800{ }^{\circ} \mathrm{C}$ and show several voltage plateaus, each of which represents a two-phase equilibrium that corresponds to a fixed $p_{\mathrm{O}_{2}}$ or $p_{\mathrm{H}_{2} \mathrm{O}} / p_{\mathrm{H}_{2}}$ according to Gibbs' phase rule. Thermodynamic assessments indicate that these plateaus correspond to the two-phase equilibria of $\mathrm{Fe}_{2} \mathrm{O}_{3}-\mathrm{Fe}_{3} \mathrm{O}_{4}$ (at $\sim 0.388$ volt), $\mathrm{Fe}_{3} \mathrm{O}_{4}-\mathrm{FeO}$ (at $\sim 0.938$ volt) and $\mathrm{FeO}-\mathrm{Fe}$ (at $\sim 0.970$ volt). The last plateau at $\sim 1.30$ volts reflects the $p_{\mathrm{O}_{2}}$ in the $\mathrm{H}_{2}$ stream (with a trace amount of $\mathrm{H}_{2} \mathrm{O}$ in pure $\mathrm{H}_{2}$ ) equilibrating with a metallic Fe phase. The solid oxide iron-air battery utilizes the $\mathrm{FeO}-\mathrm{Fe}$ phase equilibrium as a means of storing electrical-chemical energy via the following $\mathrm{H}_{2} / \mathrm{H}_{2} \mathrm{O}$-mediated reversible electrochemical-chemical looping reactions: 


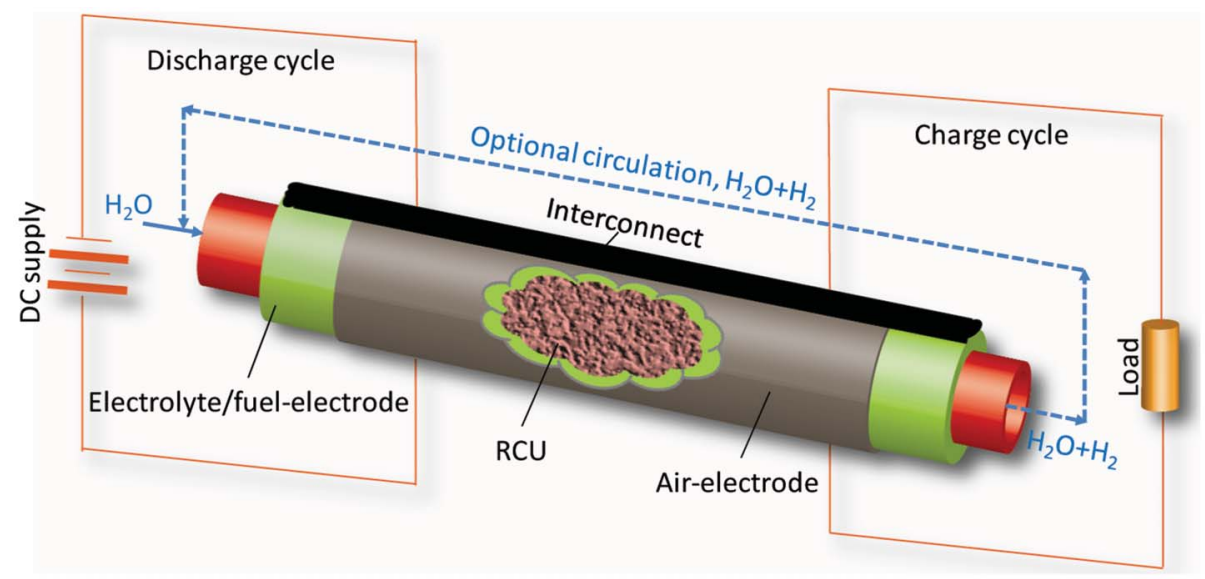

Fig. 1 Schematic of working principle of the new solid oxide based metal-air battery. An anode-supported tubular RSOEC is used for illustration purpose.

$$
\begin{aligned}
& \mathrm{H}_{2(g)}+\mathrm{O}^{2-\stackrel{\text { charge }}{\stackrel{4-\cdots}{\longrightarrow}} H_{2} \mathrm{O}_{(g)}}+2 e^{-}
\end{aligned}
$$

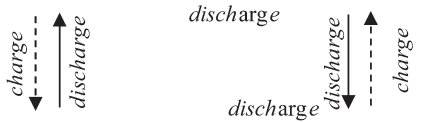

$$
\begin{aligned}
& \mathrm{H}_{2(g)}+\mathrm{FeO}_{(s)} \stackrel{\stackrel{\text { charge }}{\longleftarrow}}{\longleftarrow} \mathrm{H}_{2} \mathrm{O}_{(g)}+\mathrm{Fe}_{(s)}
\end{aligned}
$$

One pronounced feature of the new battery is its use of a separate RCU, other than the electrode itself, as the energy storage component. This design yields an EMF independent of the cycle state. Fig. 2(b) and (c) schematically illustrate the variations of $p_{\mathrm{H}_{2}} / p_{\mathrm{H}_{2} \mathrm{O}}$ and the mass ratio of the metal and metal oxide, $m_{\mathrm{Me}} /$ $m_{\mathrm{MeOx}}$ at key locations inside the battery. Since the $p_{\mathrm{H}_{2}} / p_{\mathrm{H}_{2} \mathrm{O}}$ of the reactant gas entering the RSOEC remains constant during the cycle, the energy storage process is accomplished by a corresponding change in the mass ratio of $\mathrm{Fe}$ and $\mathrm{FeO}, m_{\mathrm{Fe}} / m_{\mathrm{FeO}}$, which is precisely regulated by the $\mathrm{H}_{2} / \mathrm{H}_{2} \mathrm{O}$-mediated redox reaction. Such an EMFconstant electrochemical battery cell is advantageous compared to $\mathrm{Na}-\mathrm{S}^{8}$ and other liquid metal batteries, ${ }^{9-11}$ in which the active species is directly incorporated into or extracted from the electrode structure, producing a process-dependent EMF.
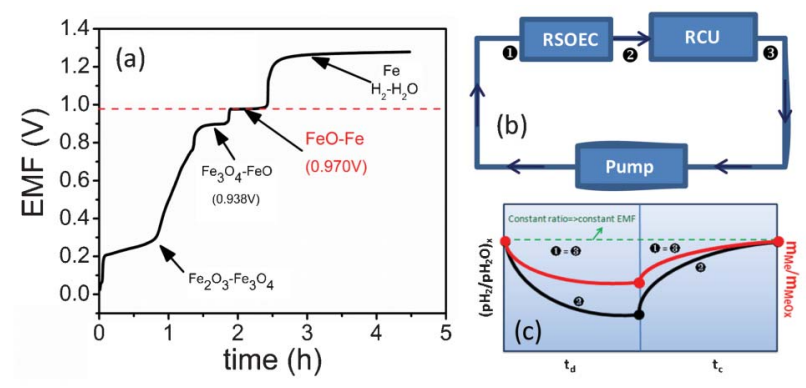

Fig. 2 (a) EMF recorded during the reduction of $\mathrm{Fe}_{2} \mathrm{O}_{3}$ by $\mathrm{H}_{2}$ at $800{ }^{\circ} \mathrm{C}$; (b) key locations inside the battery exposed to reactant gas; (c) variations of $p_{\mathrm{H}_{2}} / p_{\mathrm{H}_{2} \mathrm{O}}$ and $m_{\mathrm{Me}} / m_{\mathrm{MeOx}}$ at locations $\mathbf{1}=3$ and 2 with the state of an electrical cycle. $t_{\mathrm{d}}$ and $t_{\mathrm{c}}$ are times for discharge and charge, respectively.
The energy storage characteristics of the battery, which were investigated with $50-200 \mathrm{~mA} \mathrm{~cm}{ }^{-2}$ of current density over $10 \mathrm{~min}$ to $6 \mathrm{~h}$ of cycle duration, show that the charge storage capacity is strongly dependent on actual iron utilization $\left(U_{\mathrm{Fe}}\right)$, a key parameter reflecting the combined effect of operating current and cycle duration. The variations of battery voltage with charge storage capacities in terms of $\mathrm{mAh} \mathrm{g}^{-1} \mathrm{Fe}$ and $\mathrm{mAh} \mathrm{cm} \mathrm{c}^{-2}$ at different $U_{\mathrm{Fe}}$ are shown in Fig. 3. These two capacity terms evaluate the ability of the new battery to store electrical charge on the basis of the weight of
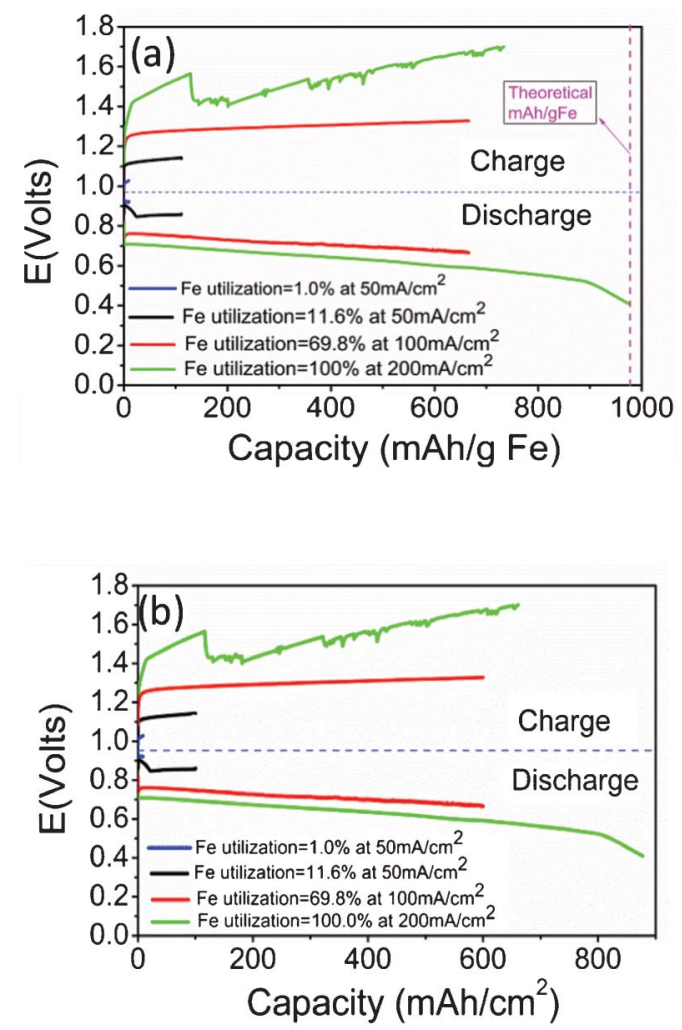

Fig. 3 Energy storage characteristics measured at different $U_{\mathrm{Fe}}$ and $800{ }^{\circ} \mathrm{C}$; (a) weight specific charge storage capacity (over $0.80 \mathrm{~g} \mathrm{Fe}$ ); (b) area-specific charge storage (over $0.88 \mathrm{~cm}^{2}$ active area of electrode). 
energy storage material and the active area of the electrode, respectively. The battery explicitly exhibits a higher charge storage capacity at a higher $U_{\mathrm{Fe}}$, but with more pronounced voltage degradation. Given the fact that the kinetic rate $\left(\right.$ moles s${ }^{-1} \mathrm{~cm}^{-2}$ ) of a redox reaction generally decreases with time (a parabolic behavior), the resulting gradual decrease in the production rates of $\mathrm{H}_{2}$ (for discharging) and $\mathrm{H}_{2} \mathrm{O}$ (for charging) during a deep charge/ discharge cycle would essentially increase the actual consumption of $\mathrm{H}_{2}$ and $\mathrm{H}_{2} \mathrm{O}$ by an RSOEC operating at a constant current, thus lowering voltage as a result of fuel starvation. Other factors, such as the loss of surface area of Fe-particles during hightemperature operation, could also add to the decline of capacity. Finally, the abrupt drop-off in voltage at $U_{\mathrm{Fe}}=100 \%$ signals the shift of the $\mathrm{Fe}-\mathrm{FeO}$ equilibrium to the adjacent oxygen-lean $\mathrm{FeO}-\mathrm{Fe}_{3} \mathrm{O}_{4}$ equilibrium. The latter possesses only one third of the $\mathrm{Fe}-\mathrm{FeO}$ redox couple's capacity, thus rendering the $\mathrm{FeO}-\mathrm{Fe}_{3} \mathrm{O}_{4}$ equilibrium unfavorable for energy storage.

The relationship between energy capacity, round-trip efficiency and $U_{\mathrm{Fe}}$ are shown in Fig. 4. Energy capacity follows the theoretical line at low $U_{\mathrm{Fe}}$, but quickly deviates to lower values at higher $U_{\mathrm{Fe}}$. There are two sources of energy loss for the observed deviation: increased voltage losses from the ohmic and polarization resistances of the RSOEC at higher current density, and raised consumption of $\mathrm{H}_{2}$ and $\mathrm{H}_{2} \mathrm{O}$ by the RSOEC, due to decreased production rates of $\mathrm{H}_{2}$ and $\mathrm{H}_{2} \mathrm{O}$ over time in the RCU. The relatively low ionic conductivity and thick yttria stabilized zirconia (YSZ) electrolyte $(150 \mu \mathrm{m})$ used in this study is a major cause of the higher energy loss. On the other hand, the observed decrease in round-trip efficiency with regard to $U_{\mathrm{Fe}}$ is attributed to the unbalanced energy inputs and outputs resulting from the RSOEC's polarization and the RCU's parabolic kinetics. Overall, the competing trend exhibited between capacity $-U_{\mathrm{Fe}}$ and efficiency $-U_{\mathrm{Fe}}$ suggests that the capacity and efficiency of the new solid oxide iron-air storage battery can be balanced with a proper choice of $U_{\mathrm{Fe}}$. One ongoing project in our group is to optimize the performance of functional materials employed in RSOEC and RCU as an effort to achieve high capacity and efficiency at high $U_{\mathrm{Fe}}$.

The cyclic stability of the battery tested over ten continuous cycles is shown in Fig. 5. For each single cycle, the performance appears to be very stable. However, a marked gradual degradation is observed after each charge cycle. The faster degradation of the discharge compared to the charge in every cycle suggests that a performance-

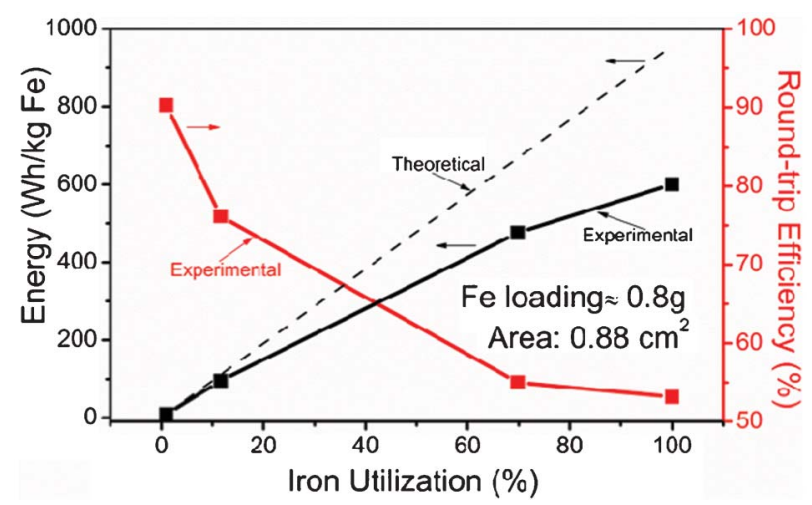

Fig. 4 Energy storage capacity and round-trip efficiency as a function of iron utilization.
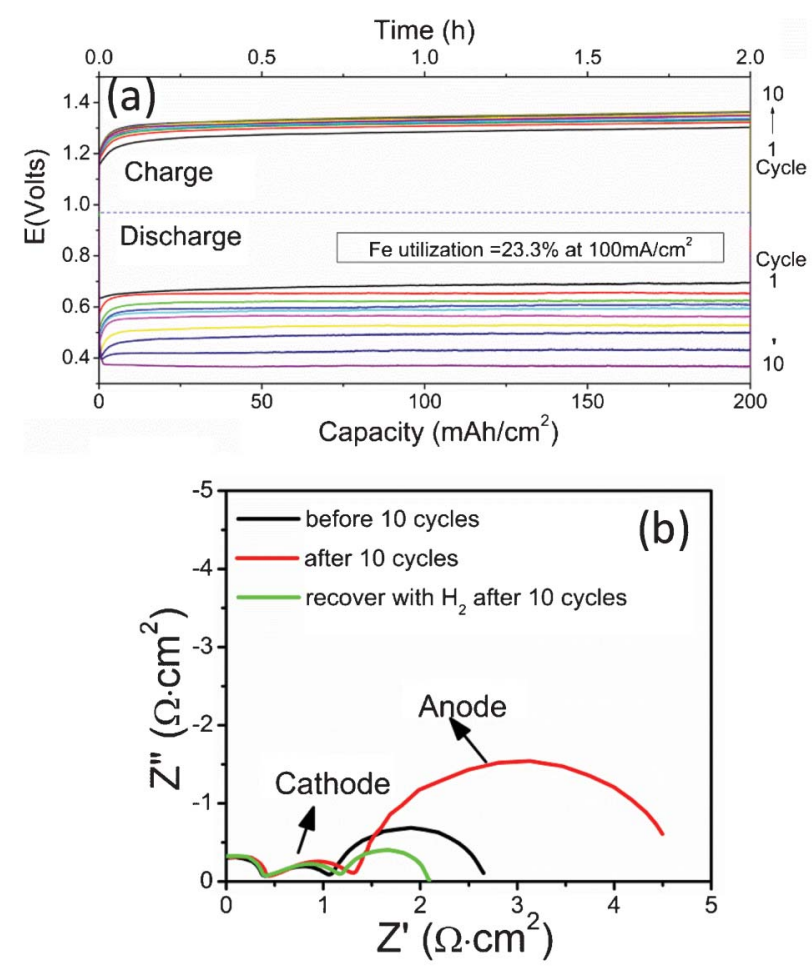

Fig. 5 (a) Cyclic stability recorded at $U_{\mathrm{Fe}}=23.3 \%$ and $800{ }^{\circ} \mathrm{C}$; (b) $\mathrm{AC}$ impedance spectra showing close association of the degradation with the fuel-electrode.

detrimental event has occurred during the charge cycle, which is accountable for the degradation found in the subsequent discharge cycle. We hypothesize the following mechanism for the degradation phenomenon. During the discharge cycle, in addition to the dominant reactions described in eqn (2) and (3), a parallel reaction between $\mathrm{FeO}_{(\mathrm{s})}$ and $\mathrm{H}_{2} \mathrm{O}_{(\mathrm{g})}$ can also take place due to its favorable thermodynamics under the battery's operating condition:

$$
\mathrm{FeO}_{(\mathrm{s})}+\mathrm{H}_{2} \mathrm{O}_{(\mathrm{g})}=\mathrm{Fe}(\mathrm{OH})_{2(\mathrm{~g})}
$$

The calculated equilibrium partial pressure of $\mathrm{Fe}(\mathrm{OH})_{2(\mathrm{~g})}, p_{\mathrm{Fe}(\mathrm{OH})_{2}}$ $=2.71 \times 10^{-8} \mathrm{~atm}\left(800^{\circ} \mathrm{C}\right)$. During the charge cycle, in addition to

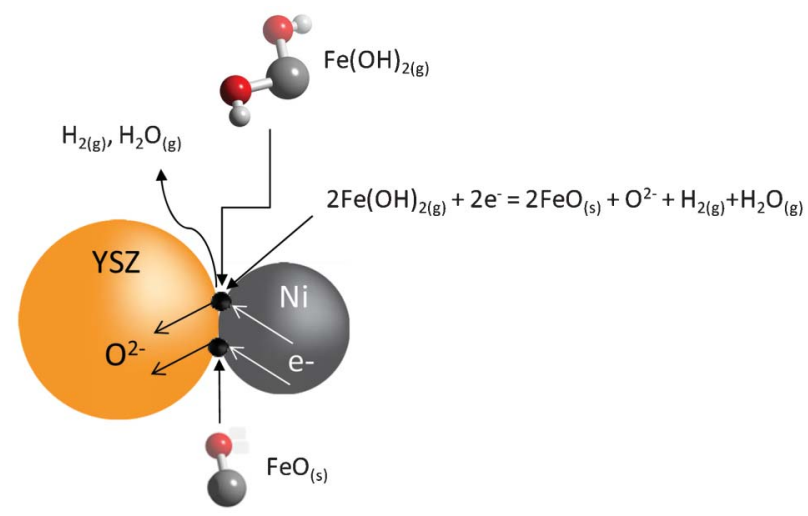

Fig. 6 Schematic of electrochemical condensation of $\mathrm{FeO}_{(\mathrm{s})}$ at the triplephase boundaries (TPBs) of the fuel-electrode. 
the dominant reactions described in eq. (2) and (3), the gaseous $\mathrm{Fe}(\mathrm{OH})_{2(\mathrm{~g})}$ can also be reduced at the three-phase boundaries (TPBs) in the fuel-electrode via the following electrochemical reaction:

$$
2 \mathrm{Fe}(\mathrm{OH})_{2(\mathrm{~g})}+2 \mathrm{e}^{-}=2 \mathrm{FeO}_{(\mathrm{s})}+\mathrm{O}^{2-}+\mathrm{H}_{2(\mathrm{~g})}+\mathrm{H}_{2} \mathrm{O}_{(\mathrm{g})}
$$

A schematic showing such an electrochemical condensation process is given in Fig. 6. A simple estimation using the equilibrium $p_{\mathrm{Fe}(\mathrm{OH})_{2}}=2.71 \times 10^{-8}$ atm indicates that as high as $0.27 \mathrm{~g} \mathrm{FeO}_{(\mathrm{s})}$ per $\mathrm{cm}^{2}$ can be deposited onto the TPBs for a $2 \mathrm{~h}$ charge cycle shown in Fig. 5(a). With the catalytically inactive $\mathrm{FeO}_{(\mathrm{s})}$ accumulating at the TPBs of the Ni-based fuel-electrode over every charge cycle, each following discharge cycle will suffer increased resistances of charge-transfer and mass-transfer as a result of decreased catalytic activity and porosity by the condensed $\mathrm{FeO}_{(\mathrm{s})}$. This interpretation is consistent with the degradation trend shown in Fig. 5(a) of the multi-cycle curves. The AC impedance spectra of pre- and post-cycle samples shown in Fig. 5(b) further support the mechanism by demonstrating that the degradation is exclusively linked to the increase in the resistance of the fuel-electrode semicircle. Finally, the proposed electrochemical condensation of $\mathrm{FeO}_{(\mathrm{s})}$ at the TPBs has also been experimentally confirmed by energy dispersive X-ray spectroscopy (EDS) analysis of the post-test fuel-electrode: Fig. S3† of Electronic Supplementary Information reveals 0.14 atom $\% \mathrm{Fe}$ in the fuel electrode. It is also interesting to note from Fig. 5(b) that the use of pure $\mathrm{H}_{2}$ can decrease the battery's resistance to a level even lower than the original one. In line with the proposed model, this improvement can be reasonably understood as a result of freshly reduced fine particles of $\mathrm{Fe}_{(\mathrm{s})}$ from the electrochemically condensed $\mathrm{FeO}_{(\mathrm{s})}$, and their increased catalytic activity for electrochemical oxidation of $\mathrm{H}_{2}$ when combined with $\mathrm{Ni}_{(\mathrm{s})}$. ${ }^{12}$

In conclusion, the new solid oxide iron-air rechargeable battery has demonstrated the potential for high charge and energy storage capacities, as well as high efficiency. The capacity and efficiency characteristics of this battery are strongly dependent on the degree of iron utilization: higher charge and energy storage capacity, but lower round-trip efficiency, can be produced at higher iron utilization, and lower charge and energy storage capacity, but higher round-trip efficiency, can be produced at lower iron utilization. Improving electrochemical performance of the RSOEC components and catalytic activity of the RCU materials are attractive approaches to boost efficiency while maintaining high capacity. On the other hand, studies of the battery's cycle life reveal a unique charge-cycle originated degradation mechanism. A combined vapor-phase transport and electrochemical condensation mechanism is proposed to interpret the degradation behavior, which is favorably confirmed by EDS analysis of the post-test sample. Overall, the presented fundamental findings are essential to the successful development and deployment of an efficient, cost effective, environmentally friendly, and sustainable solid oxide metal-air rechargeable battery for grid energy storage. Recent efforts in our laboratory have been devoted to lowering the battery's operating temperature to the 600 $650{ }^{\circ} \mathrm{C}$ range as a means of improving the cyclic stability, as well as designing and eventually testing a hundred-watt multi-battery bundle/stack system operating at a practically meaningful voltage and current density.

\section{Acknowledgements}

The authors acknowledge the Solid Oxide Fuel Cell Center of Excellence and Department of Mechanical Engineering in the University of South Carolina for providing seed funding to this work.

\section{References}

1 P. Poizot and F. Dolhem, Energy Environ. Sci, 2011, 4, 2003-2019.

2 T. R. Cook, D. K. Dogutan, S. Y. Reece, Y. Surendranath, T. S. Teets and D. G. Nocera, Chem. Rev., 2010, 110, 6474-6502.

3 C. J. Yang and R. B. Jackson, Renewable Sustainable Energy Rev., 2011, 15, 839-844.

4 Z. Yang, J. Zhang, M. C. W. Kintner-Meyer, X. Lu, D. Choi, J. P. Lemmon and J. Liu, Chem. Rev., 2011, 111, 3577-3613.

5 J. P. Barton and D. G. Infield, IEEE Trans. Energy Convers., 2004, 19, 441-448.

6 R. Saidur, N. A. Rahim and M. Hasanuzzaman, Renewable Sustainable Energy Rev., 2010, 14, 1135-1153.

7 N. Xu, X. Li, X. Zhao, J. B. Goodenough and K. Huang, Energy Environ. Sci., 2011, 4, 4942-4946.

8 T. Oshima, M. Kajita and A. Okuno, Int. J. Appl. Ceram. Technol., 2004, 1, 269-276.

9 D. J. Bradwell, H. Kim, A. H. C. Sirk and D. R. Sadoway, J. Am. Chem. Soc., 2012, 134, 1895-1897.

10 H. Shimotake, G. Rogers and E. J. Cairns, Ind. Eng. Chem. Process Des. Dev., 1969, 8, 51-56.

11 E. J. Cairns and H. Shimotake, Science, 1969, 164, 1347-1355.

12 H. Kan and H. Lee, Catal. Commun., 2010, 12, 36-39. 